\title{
Oocyte maturation and quality: role of cyclic nucleotides
}

\author{
R B Gilchrist ${ }^{1}$, A M Luciano ${ }^{2}$, D Richani ${ }^{1}, \mathrm{HT}$ Zeng $^{3}$, X Wang ${ }^{1,4}$, M De Vos ${ }^{5}$, S Sugimura ${ }^{6}$, \\ J Smitz ${ }^{5}$, F J Richard ${ }^{7}$ and J G Thompson ${ }^{8}$ \\ ${ }^{1}$ Discipline of Obstetrics and Gynaecology, School of Women's and Children's Health, University of New South \\ Wales, Sydney, New South Wales, Australia, ${ }^{2}$ Reproductive and Developmental Biology Laboratory, Department of \\ Health, Animal Science and Food Safety, University of Milan, Milano, Italy, ${ }^{3}$ Center for Reproductive Medicine, \\ Sixth Affiliated Hospital, Sun Yat-sen University, Guangzhou, People's Republic of China, ${ }^{4}$ Department of Obstetrics \\ and Gynaecology, St George Public Hospital, Sydney, Australia, ${ }^{5}$ Follicle Biology Laboratory, University Hospital \\ UZBrussel, Medical School, Vrije Universiteit Brussel, Brussels, Belgium, ${ }^{6}$ Institute of Agriculture, Department of \\ Biological Production, Tokyo University of Agriculture and Technology, Tokyo, Japan, ${ }^{7}$ Centre de Recherche \\ en Biologie de la Reproduction, Département des Sciences Animales, Faculté des sciences de l'agriculture et de \\ I'alimentation, Université Laval, Québec, Canada, and ${ }^{8}$ School of Medicine, Robinson Research Institute and ARC \\ Centre of Excellence for Nanoscale BioPhotonics, The University of Adelaide, Adelaide, South Australia, Australia
}

Correspondence should be addressed to R B Gilchrist; Email: r.gilchrist@unsw.edu.au

\begin{abstract}
The cyclic nucleotides, cAMP and cGMP, are the key molecules controlling mammalian oocyte meiosis. Their roles in oocyte biology have been at the forefront of oocyte research for decades, and many of the long-standing controversies in relation to the regulation of oocyte meiotic maturation are now resolved. It is now clear that the follicle prevents meiotic resumption through the actions of natriuretic peptides and cGMP - inhibiting the hydrolysis of intra-oocyte cAMP - and that the pre-ovulatory gonadotrophin surge reverses these processes. The gonadotrophin surge also leads to a transient spike in cAMP in the somatic compartment of the follicle. Research over the past two decades has conclusively demonstrated that this surge in cAMP is important for the subsequent developmental capacity of the oocyte. This is important, as oocyte in vitro maturation (IVM) systems practised clinically do not recapitulate this cAMP surge in vitro, possibly accounting for the lower efficiency of IVM compared with clinical IVF. This review particularly focuses on this latter aspect - the role of cAMP/cGMP in the regulation of oocyte quality. We conclude that clinical practice of IVM should reflect this new understanding of the role of cyclic nucleotides, thereby creating a new generation of ART and fertility treatment options.

Reproduction (2016) 152 R143-R157
\end{abstract}

\section{Introduction}

Oocyte maturation and oocyte quality are fundamental to fertility in all mammalian species. These are evident in modern human infertility treatment in which oocyte quantity and quality are rate limiting to the success of nearly all artificial reproductive technologies (ART). We now know a great deal about the regulation of oocyte maturation. It has long been recognised that one of the most important classes of molecules regulating mammalian oocyte maturation are the cyclic nucleotides, namely, cyclic adenosine $3^{\prime}, 5^{\prime}$-monophosphate (cAMP) and cyclic guanosine $3^{\prime}, 5^{\prime}$-monophosphate (cGMP). These, in particular cAMP, have been the subject of intensive oocyte research for the past 40 years.

The earliest report on the role of cAMP used a permeable cAMP, dibutyryl cAMP (dbcAMP), demonstrating oocytes can be maintained in meiotic arrest in vitro after removal from their follicular environment (Cho et al. 1974). Since then, cAMP and CGMP and their roles in the regulation of oocyte maturation remain intensively researched worldwide. This research largely focused on the regulation of meiosis and the role of the nucleotides in the maintenance of meiotic arrest and the resumption of meiosis, principally using rodent models (reviews from that period; (Dekel 1988, Eppig 1989)). This research area was complicated by the CAMP paradox, whereby high levels of oocyte cAMP maintain oocyte meiotic arrest, but at the time of ovulation high follicular levels of cAMP induce meiotic resumption (Dekel et al. 1988). Understanding the mechanisms regulating oocyte meiotic resumption was further complicated by the controversy over the participation of falling cAMP levels and the simultaneous loss of cumulusoocyte gap junctional communication (GJC). Many of the controversies of that period are now settled following landmark discoveries, including the role 
of phosphodiesterases (PDEs) (Tsafriri et al. 1996, Masciarelli et al. 2004), the sources and roles of cAMP (Mehlmann et al. 2002) and cGMP in the oocyte (Norris et al. 2009, Vaccari et al. 2009), and the participation of natriuretic peptides (Zhang et al. 2010).

Hence, today we have a thorough understanding of the participation of CAMP and cGMP in the regulation of mammalian oocyte meiosis. However, it is striking that the large numbers of studies from the 1970s to 1990s, principally in mice, were largely limited to investigating oocyte meiosis and did not follow the oocyte's subsequent capacity to support embryo development or oocyte developmental competence. Curiously, even today, this central function of oocytes is not typically studied by mouse oocyte developmental biologists, but rather is the subject of major research efforts conducted by domestic animal oocyte biologists. It was first discovered in bovine and porcine oocytes that the spike of follicular cAMP that occurs at ovulation is important for the oocyte's subsequent capacity to support embryo development (Aktas et al. 1995, Funahashi et al. 1997). This important discovery has led to a whole new area of research over the past two decades, which has shifted the focus of cyclic nucleotides away from oocyte meiosis towards oocyte developmental competence or oocyte quality, and how this is applied to improve outcomes in the context of ART.

\section{Cyclic nucleotides and oocyte maturation in vivo Cyclic nucleotides maintain meiotic arrest}

Follicle maintains meiotic arrest

A basic tenant of oocyte maturation is that oocytes in midsized antral and pre-ovulatory follicles are competent to undergo oocyte meiotic maturation but are arrested at the germinal vesicle (GV) stage of meiosis by the follicle environment. Hence, oocytes removed from the follicle and placed in vitro will undergo hormone-independent, spontaneous meiotic maturation (Pincus \& Enzmann 1935, Edwards 1965). It is the cyclic nucleotides, cAMP and cGMP, of follicular somatic and germ cell origin that are the principal molecules responsible for maintaining oocyte meiotic arrest.

\section{Follicle endows the oocyte with developmental competence}

During folliculogenesis, oocytes undergo changes at both the nuclear and cytoplasmic levels that confer the oocyte with developmental competence, defined as the capacity to support pre-implantation embryo development (Gilchrist \& Thompson 2007). Among other processes, changes in large-scale oocyte chromatin structure are essential for the onset of developmental competence (reviewed in Luciano \& Lodde 2013).
The proper maintenance of cumulus cell (CC)-oocyte gap junctional communication $(\mathrm{GJC})$ appears to have a crucial role in chromatin remodelling and the gradual transcriptional silencing processes that occur in fully grown oocytes, from early antral through to the latter half of antral folliculogenesis (De La Fuente \& Eppig 2001, Lodde et al. 2008). CC-oocyte GJCs in turn are regulated by cyclic nucleotides, as $\mathrm{FSH}$ or a range of cAMP-modulating pharmaceuticals sustain functional CC-oocyte communication (Luciano et al. 2004, Thomas et al. 2004a, Atef et al. 2005, El-Hayek \& Clarke 2015). In addition, treatment with FSH in vivo leads to oocyte chromatin condensation and suppression of transcription (Zuccotti et al. 1998, De La Fuente \& Eppig 2001). The use of bovine cumulus-oocyte complex (COC) culture systems that prolong GJC, sustain oocyte growth and allow early chromatin compaction events is associated with the oocyte acquiring the ability to mature and be fertilised in vitro (Luciano et al. 2011). However, when GJ functionality is experimentally interrupted, chromatin rapidly condenses and RNA synthesis abruptly ceases. Interestingly, this effect is nullified by preventing CAMP hydrolysis specifically within the oocyte (Luciano et al. 2011). The preservation of an appropriate cAMP content in the oocyte, even in the absence of functional GJC, is able to prevent the abrupt condensation of chromatin. This suggests that the cAMP cascade is the likely regulator of GJ-mediated actions on chromatin remodelling. These findings suggest that cAMP could be involved in the control of the activity of factors that modulate oocyte transcription and largescale chromatin remodelling in fully grown oocytes during their final phase of development, immediately before the resumption of meiosis.

\section{CAMP control of meiotic arrest}

It has long been known that moderate to high intraoocyte levels of the second messenger, CAMP, maintain oocyte meiotic arrest (Cho et al. 1974). Cyclic AMP is synthesised from ATP by an active adenylyl cyclase (AC). In rodent oocytes, $\mathrm{AC} 3$ has been reported to be present and functional (Horner et al. 2003). GPR3 is a functional receptor found in the oocyte, and hence the oocyte can independently synthesise cAMP (Olsiewski \& Beers 1983, Mehlmann et al. 2002). However, a major source of intraoocyte cAMP is the somatic cells surrounding the oocyte by virtue of the electrophysiological syncytium between the oocyte, cumulus and granulosa cells. Activation of CC ACs by FSH or forskolin loads the oocyte with cAMP, increasing CAMP concentrations in the oocyte manyfold (Thomas et al. 2002). Sustained levels of intra-oocyte cAMP activate protein kinase A (PKA), which in turn prevent the activation of maturation-promoting factor, retaining the oocyte in the M-phase. Cyclic nucleotide participation in the control of the meiotic cell cycle is reviewed elsewhere (Downs 2010, Conti et al. 2012). 


\section{CGMP and phosphodiesterases}

The oocyte possesses a potent PDE that must be kept in check to maintain meiotic arrest. The study of oocyte PDEs began several decades ago, when it was found that non-specific PDE inhibitors, such as theophylline (Cho et al. 1974) and 3-isobutyl-1-methylxanthine (IBMX) (Magnusson \& Hillensjo 1977, Dekel \& Beers 1978), maintain meiotic arrest of oocytes in vitro. Two studies published in the 1990s reported the presence of a specific family of PDEs within the rodent oocyte, namely PDE3A, identified using in situ hybridisation (Reinhardt et al. 1995) and sub-type-specific PDE inhibitors such as milrinone and cilostamide (Tsafriri et al. 1996). Several years later, activity of the oocyte PDE3 was shown to increase before both spontaneous and gonadotrophin-induced meiotic resumption (Richard et al. 2001). The effect of specific PDE3 inhibitors on maintaining oocyte meiotic arrest in vitro has now been demonstrated across many mammalian species: rats (Tsafriri et al. 1996), mice (Wiersma et al. 1998), cattle (Mayes \& Sirard 2002, Thomas et al. 2002), monkeys (Jensen et al. 2002), humans (Nogueira et al. 2003a) and swine (Laforest et al. 2005). Demonstration of sterility of female mice bearing a PDE3A-null mutation due to the ovulation of GV-stage oocytes was the final proof of the central role of $\mathrm{PDE} 3 \mathrm{~A}$ in maintaining oocyte meiotic arrest (Masciarelli et al. 2004).

PDEs are organised into 11 families with differing PDE isoenzymes capable of hydrolysing CAMP or cGMP or both nucleotides. An important finding was that PDE3A, which is the prominent PDE in the oocyte, is a cGMP-inhibited cAMP-hydrolysing enzyme (Maurice \& Haslam 1990). It was long known that cGMP is an oocyte maturation inhibitor (Hubbard \& Terranova 1982) and that ovarian levels of cGMP decline after LH stimulation (Ratner 1976). After three decades, its significance became apparent when two key papers revealed that cGMP permeating from the granulosa/CC compartment into the oocyte via gap junctions inhibits the oocyte's PDE3A (Norris et al. 2009, Vaccari et al. 2009). Hence, cGMP from the follicular somatic cells maintains sufficient intra-oocyte cAMP to maintain the oocyte in meiotic arrest (Fig. 1).

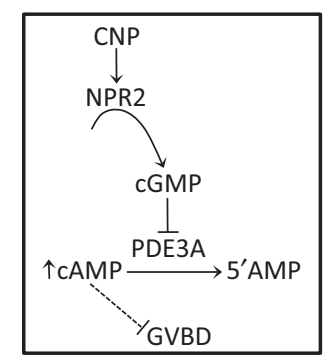

Figure 1 The coordination between CNP, cGMP and cAMP in the control of oocyte meiotic arrest. See text for abbreviations.

\section{Contribution of natriuretic peptides to meiotic arrest}

The signalling model for the maintenance of meiotic arrest has recently been enhanced by the discovery of the important roles of the natriuretic peptides. The natriuretic peptide family is composed of three major types: atrial natriuretic peptide, brain natriuretic peptide and C-type natriuretic peptide (CNP). A study showed that granulosa cells secrete CNP and CCs express its receptor, NPR2, which is a member of the guanylyl cyclase receptor family. NPR2 stimulation by CNP increased cGMP intracellular concentrations in both CCs and the oocyte and maintained meiotic arrest (Zhang et al. 2010). CNP has since been identified as an oocyte-meiosis-inhibiting peptide in a range of species such as mice (Zhang et al. 2010), swine (Santiquet et al. 2014), cattle (Franciosi et al. 2014) and rats (Zhang et al. 2015). The physical characteristics and mode of action of CNP suggest it is likely to be the oocyte maturation inhibitor (OMI) found in follicular fluid, as described several decades ago (Tsafriri et al. 1976). This knowledge now provides us with a logical model, whereby the follicular compartment maintains oocyte meiotic arrest in vivo by supplying CNP-induced cGMP from the granulosa/CCs, via gap junctions, to the oocyte to inhibit PDE3A, thereby maintaining sufficient cAMP to inhibit GV breakdown (GVBD; Fig. 1).

\section{Ovulatory cascade}

\section{LH-induced changes in cyclic nucleotides}

The pre-ovulatory surge of LH induces oocyte maturation, but neither oocytes nor CCs express LH receptors, so how does the LH surge lead to oocyte maturation? The exact cellular mechanisms and sequences of events that transduce the LH signal from the mural granulosa cells to the oocyte have been the topic of intense debate for decades. It is not the intention of this review to delve into these debates; fortunately, this is reviewed comprehensively elsewhere (Downs 2010).

$\mathrm{LH}$ induces an acute transient spike in cAMP in the somatic compartment of the follicle. This is of the order of an 80-200-fold increase in CAMP, depending on the compartment measured (Tsafriri et al. 1972, Yoshimura et al. 1992, Mattioli et al. 1994, Albuz et al. 2010). The spike in CAMP appears, in general, to occur before GVBD, with levels falling sharply at around the time of GVBD. There is contradictory evidence as to whether the $\mathrm{LH}$-induced spike in CAMP is transmitted into the oocyte (Yoshimura et al. 1992, Norris et al. 2009). This pre-ovulatory spike in CAMP is able to induce meiosis, as CAMP pulsing of explanted follicles or isolated COCs in vitro induces the resumption of meiosis in the presence of inhibitors (Tsafriri et al. 1972, Dekel et al. 1981, Downs et al. 1988). Hence, the acute changes in CAMP concentrations that follow the gonadotrophin surge play a significant role in oocyte function, and 
this is an important point to note for cAMP-mediated oocyte in vitro maturation (IVM) systems (see 'Cyclic nucleotides and oocyte quality' section).

Despite this ovulatory pulse in follicular cAMP levels, activation of the oocyte PDE3A and a consequent fall in intra-oocyte cAMP are clearly a prerequisite for de-phosphorylation of PKA, and activation of maturationpromoting factor (MPF) and meiotic resumption (Fig. 2). How is the rapid loss of oocyte cAMP achieved? LH administration leads to a fall in follicular cGMP (Hubbard 1986) and a loss of gap junctions (SelaAbramovich et al. 2005). The involvement of cGMP in the process of meiotic resumption was recently strengthened by the work of Shuhaibar et al. (Shuhaibar et al. 2015). Using follicles from mice expressing a FRET sensor, real-time monitoring of cGMP showed that within 1 min of LH exposure, cGMP concentrations start to decrease from the peripheral granulosa cells and by 20 min the concentration of cGMP decreased by more than 20-fold and was uniformly low across the follicle (Shuhaibar et al. 2015). Consequently, it is likely that oocyte cAMP concentration decreases because of the relief of the inhibitory actions of CGMP on PDE3A in the oocyte (Norris et al. 2009, Vaccari et al. 2009).

CNP activation of the NPR2 guanylyl cyclase is a principal source of cGMP in the follicle (Zhang et al. 2010), and LH downregulates CNP transcript expression in mouse granulosa cells and CNP protein in follicular fluid (Kawamura et al. 2011). In human, an ovulatory dose of hCG results in a decrease in CNP levels in follicular fluid (Kawamura et al. 2011). LH induces a decrease in NPR2 guanylyl cyclase activity within 20 min (Robinson et al. 2012), which can be explained

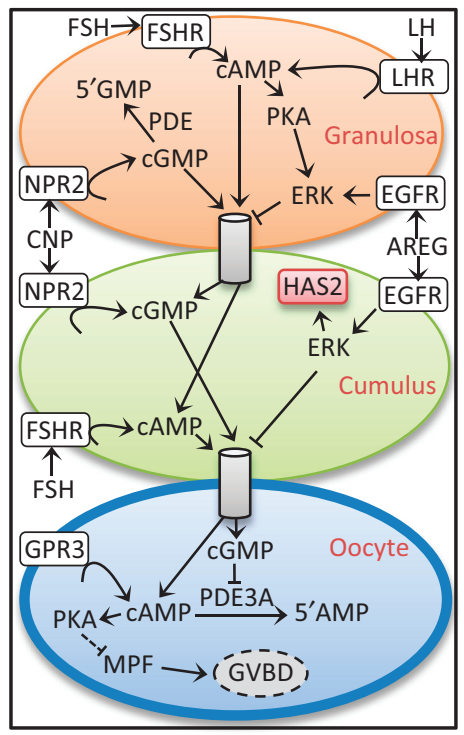

Figure 2 The cyclic nucleotides transmit the ovulatory cascade from the somatic to germ cell compartment of the follicle, instructing the oocyte to resume meiosis in the preparation for ovulation. See text for abbreviations. by de-phosphorylation and inactivation of NPR2 in granulosa cells (Egbert et al. 2014). Hence, the present model of oocyte meiotic resumption is that $\mathrm{LH}$ induces a spike in follicular CAMP and a simultaneous decline in CNP and cGMP, leading to activation of oocyte PDE3A causing a decline in intra-oocyte cAMP sufficient to activate MPF that leads to meiotic resumption (Fig. 2).

\section{LH surge and CAMP spike activate the EGF network}

The cAMP spike within the mural granulosa cells initiates a signal transduction cascade that activates the EGF receptor-ERK1/2 pathway to induce oocyte maturation and ovulation. LH-induced CAMP production rapidly upregulates the production of EGFlike peptides (EGF-p) amphiregulin, epiregulin and betacellulin to induce EGF receptor-ERK1/2 pathway signalling (Park et al. 2004, Ashkenazi et al. 2005, Shimada et al. 2006, Fan et al. 2009). Transcription of EGF-p is induced by cAMP activation of PKA, leading to the activation of the CAMP-response element (CRE) site in the gene's promoter region via a p38MAPKCREB-dependent process (Richards 2001, Shimada et al. 2006, Fan et al. 2009). Mature form EGF-p are cleaved from mural granulosa cells and bind to the EGF receptor (ERBB1), expressed on mural granulosa cells (autocrine) as well as on CCs (paracrine) (Hsieh et al. 2007, Yamashita et al. 2007). Ligand binding in both cell types leads to receptor dimerisation and auto-phosphorylation on multiple tyrosine residues, which induce downstream RAS and, ultimately, ERK1/2 activation (Yamashita et al. 2007, Fan \& Richards 2010). ERK1/2 consequently promotes the production of prostaglandin E2 by upregulating prostaglandin synthase 2 expression. Prostaglandin E2 then acts through the prostaglandin receptor PTGER2, expressed in both granulosa cell types, to induce further production of the EGF-p by activation of the CAMP-PKA-CREB pathway (Shimada et al. 2006), thus perpetuating the maturation-inducing stimulus in the LH-unresponsive CCs. Hence, LH-induced upregulation of the cAMP-EGF-p-ERK1/2 signalling axis is involved in CC expansion, decreasing somatic cell cGMP, closure of GJs, and possibly a meiosisinducing stimulus of CC origin (Su et al. 2002, Norris et al. 2010, Chen et al. 2013).

\section{Loss of gap junctions}

In the mammalian ovary, intercellular coupling between oocyte and CCs undergoes dynamic changes during follicle development (Anderson \& Albertini 1976), and the patency of GJC between the oocyte and CC compartments decreases in parallel with the meiotic resumption of the oocyte (Eppig 1982, Larsen et al. 1986). In both in vivo and IVM, the progressive disruption of GJC occurs concomitantly with the retraction and degeneration of CC transzonal projections 
(Hyttel et al. 1986). Whether this pre-ovulatory loss of CC-oocyte GJC causes meiotic resumption due to the termination of cAMP transfer from CCs to oocyte, as originally hypothesised (Dekel \& Beers 1978), has remained the subject of much debate for decades. There is strong evidence supporting the hypothesis that diffusion of cGMP from the oocyte to the somatic compartment through functional GJs during GVBD has a crucial role in the re-initiation of meiosis (Norris et al. 2009, Vaccari et al. 2009, Shuhaibar et al. 2015).

\section{Cyclic nucleotides and oocyte quality}

\section{In vitro maturation (IVM)}

Understanding the role of cyclic nucleotides in oocyte maturation has important practical applications in ART, particularly in oocyte IVM. IVM is an ART in which COCs are collected at the immature GV stage from unstimulated or FSH-primed ovaries and matured as intact COCs in vitro before fertilisation (Edwards 1965). The most significant application of IVM is in the global production of livestock species, especially cattle. It is also conducted in other domestic species, including pigs, sheep, goats, deer, cats, camels and horse, but to a much less extent compared with cattle breeding. Global cattle embryo production by IVM/IVF exceeded 400,000 in 2013 (Perry 2014), with growth predicted to continue. Nevertheless, this figure is likely a gross underestimation. Based on this method, immature oocytes are harvested from cows usually without exogenous hormone treatment, often on a regular basis (e.g. monthly) even during early pregnancy. Thus, it leads to shortening of the intergenerational interval and genetic enrichment. In this industry, IVM is widely regarded as routine and safe.

IVM has proved less successful in humans. Its use and further development as a fertility treatment have been relatively limited compared with classical IVF following hormonal stimulation of ovaries. The principal reason for the poor uptake of human IVM appears to be its lower efficiency at generating pregnancies compared with conventional IVF, and not due to safety concerns (Buckett et al. 2007, Kuhtz et al. 2014, Spits et al. 2015) or other practical aspects of the technology. Women with polycystic ovaries (PCO) are excellent candidates for treatment with IVM because of their high number of antral follicles that can be aspirated for oocyte retrieval. In addition, these women have a particularly increased risk of ovarian hyperstimulation syndrome, a potentially life-threatening iatrogenic complication of gonadotrophin stimulation, which has never been reported after IVM treatment. IVM is principally used for women with PCO. However, an important new application of IVM is also used for fertility preservation in young women who are diagnosed with cancer and who face a substantial risk of gonadotoxicity secondary to chemotherapy or radiotherapy. For these women, for whom time is usually pressing, IVM is advantageous as it is possible to harvest oocytes at short notice without prior hormone therapy and without elevated oestrogen levels, which is contraindicated in the cases of hormonesensitive tumours (De Vos et al. 2014).

In the context of modern milder approaches to ART and the increasing demand from patients for a simpler, cheaper, more patient-friendly reproductive technology, the search for improvements in IVM are continuing and improved pregnancy rates have recently been established by a number of centres (Junk \& Yeap 2012, Ortega-Hrepich et al. 2013, Walls et al. 2015a). Nonetheless, the reduced pregnancy rates per cycle compared with conventional IVF represents a major obstacle that needs to be overcome for widespread uptake of IVM. This lower efficiency manifests at multiple levels: particularly lower metaphase II rates (typically 50-60\%), but also lower subsequent embryo development rates (Walls et al. 2015b), and in some centers, higher miscarriage rates. The use of cAMP modulators in human IVM offers great promise to improve pregnancy rates. Animal data obtained from more than 10 years of research using various CAMPmodulated IVM systems provide evidence that IVM efficiency and pregnancy outcomes can be improved by controlling CAMP levels during IVM.

\section{Cyclic AMP-mediated IVM Systems}

This section reviews the various oocyte IVM systems/ technologies pertaining to IVM regulated by the

Table 1 Pharmacological agents used in IVM to manipulate cyclic nucleotides.

\begin{tabular}{lll}
\hline Agent & Mode of action & Remarks \\
\hline $\begin{array}{l}\text { Hypoxanthine, IBMX } \\
\text { Org9935, cilostamide, milrinone }\end{array}$ & PDE inhibitors: broad spectrum & Act on CC and oocyte PDEs to prevent cAMP hydrolysis \\
& & $\begin{array}{c}\text { Target the PDE in the oocyte (PDE3A) to prevent intra-oocyte cAMP } \\
\text { hydrolysis }\end{array}$ \\
Rolipram & PDE4-specific inhibitor & Target the PDE in CC and MGC (PDE4) to prevent cAMP hydrolysis \\
Dipyridamole & PDE8-specific inhibitor & Inhibits PDE8 in CCs (bovine) to prevent cAMP hydrolysis \\
CNP & NPR2 agonist & Stimulates CC and MGC cGMP synthesis thereby antagonising PDE \\
Sildenafil & PDE5 and PDE6 inhibitor & Target CC and MGC PDEs to prevent cGMP hydrolysis \\
$\begin{array}{l}\text { Forskolin, iAC } \\
\text { dbcAMP, 8-bromo-CAMP }\end{array}$ & AC activators & Elevate CC/oocyte CAMP \\
\hline
\end{tabular}

AC, adenylate cyclase; CC, cumulus cell; CNP, C-type natriuretic peptide; dbcAMP, dibutyryl cAMP; IBMX, 3-isobutyl-1-methylxanthine; MGC, mural granulosa cell; NPR2, natriuretic peptide receptor 2; PDE, phosphodiesterase. 
cyclic nucleotides. The modes of actions of some pharmacological agents used to manipulate cyclic nucleotides in IVM are listed in Table 1. IVM systems are broadly divided into four approaches (Fig. 3), although some may overlap. Although standard IVM is used in human and veterinary clinical practice, the other three approaches can be considered at the preclinical stage of development, which has shown

\section{A Standard IVM}

B

$$
\text { Biphasic IVM }
$$
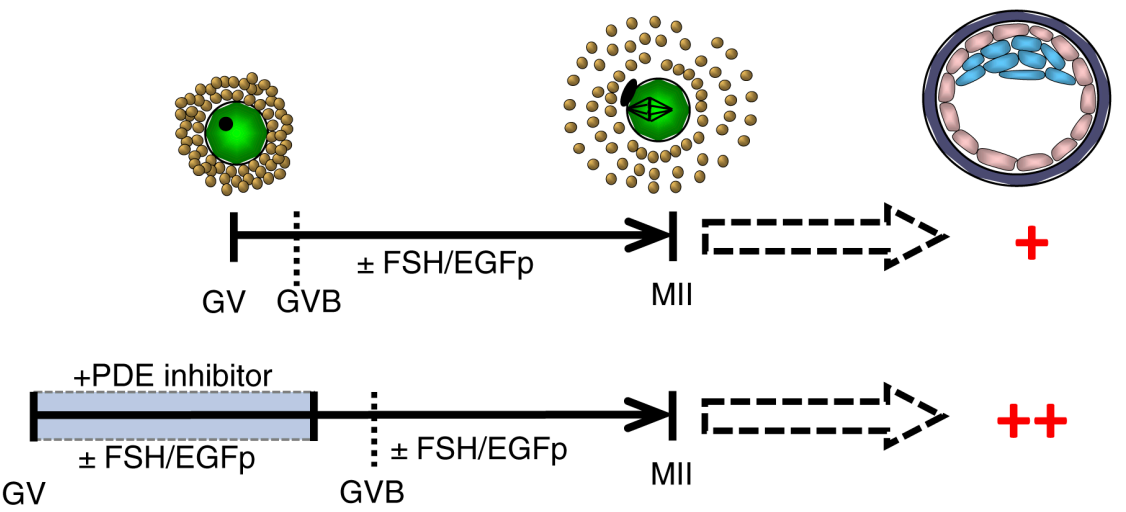

C Induced IVM (moderate cAMP)

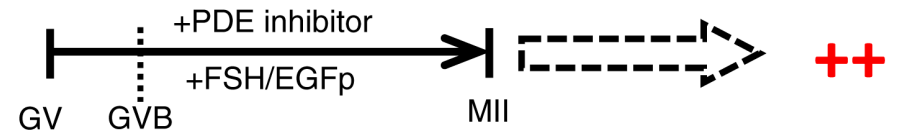

D

\section{Induced IVM (high cAMP)}
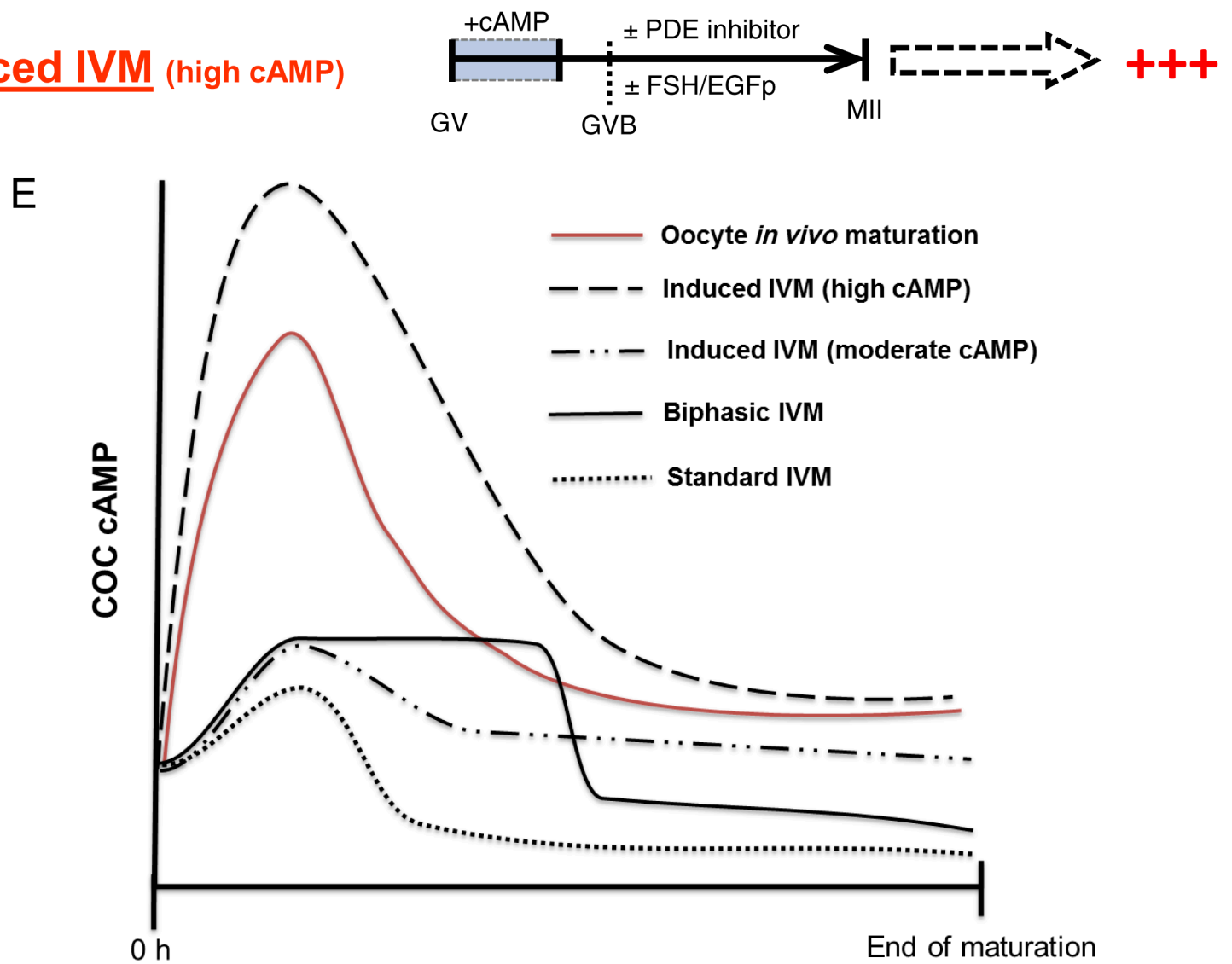

Figure 3 Differing approaches to cAMP-mediated IVM. Schematic comparison of standard IVM containing FSH but no cAMP-modulating agents (A) to various cAMP-mediated IVM systems, including (B) biphasic IVM using a PDE inhibitor for the first phase followed by washout and PDE inhibitor free in the second phase, (C) induced IVM producing moderate cAMP levels, where oocytes are matured in the simultaneous presence of PDE inhibitor and an inducing ligand, and (D) induced IVM where exogenous cAMP or AC activators produce high levels of COC cAMP. (E) Schematic illustration of actual and predicted COC cAMP levels in the differing IVM systems containing FSH compared with standard IVM and in oocytes matured in vivo. In the absence of FSH in standard IVM, COC cAMP levels decrease rather than increase (modified from (Thompson \& Gilchrist 2013)). EGF-p, epidermal growth factor-like peptides; GV, germinal vesicle; GVB, germinal vesicle breakdown; MII, metaphase II; PDE, phosphodiesterase. 
Table 2 Effect of cAMP-mediated IVM on subsequent oocyte developmental competence.

\begin{tabular}{|c|c|c|c|c|}
\hline IVM system & cAMP modulator & Species & $\begin{array}{l}\text { Effect on oocyte } \\
\text { developmental } \\
\text { competence* }\end{array}$ & References \\
\hline \multirow[t]{9}{*}{ Biphasic IVM (moderate cAMP) } & \multirow{2}{*}{ Org 9935} & Human & None & Nogueira et al. (2006) \\
\hline & & Murine & Improved & Nogueira et al. (2003b) \\
\hline & \multirow[t]{4}{*}{ Cilostamide } & Human & None & Vanhoutte et al. (2007) \\
\hline & & Human & Improved & Vanhoutte et al. $(2009 a, b)$ \\
\hline & & Bovine & Improved & Luciano et al. (2011) \\
\hline & & Porcine & Improved & Dieci et al. (2013) \\
\hline & \multirow{2}{*}{ IBMX } & Bovine & Improved & Lodde et al. (2013) \\
\hline & & Porcine & Improved & Kawashima et al. (2008) \\
\hline & CNP & Bovine & Improved & Franciosi et al. (2014) \\
\hline \multirow{5}{*}{ Induced IVM (moderate cAMP) } & \multirow{2}{*}{ Milrinone } & Bovine & Improved & Thomas et al. (2004b) \\
\hline & & Porcine & None & Grupen et al. (2006) \\
\hline & Rolipram & Bovine & Improved & Thomas et al. (2004b) \\
\hline & Dipyridamole & Bovine & Decreased & Sasseville et al. (2009) \\
\hline & Hypoxanthine & Murine & None & Downs et al. (1986) \\
\hline \multirow[t]{10}{*}{ Induced IVM (high cAMP) } & \multirow[t]{2}{*}{ dbcAMP } & \multirow[t]{2}{*}{ Porcine } & Improved & $\begin{array}{l}\text { Funahashi et al. (1997), Somfai et al. (2003), } \\
\text { Bagg et al. (2006), Kim et al. (2008), Akaki et al. (2009), } \\
\text { Nascimento et al. (2010), Sugimura et al. (2015) }\end{array}$ \\
\hline & & & None & Park and Yu (2013), Appeltant et al. (2015) \\
\hline & \multirow[t]{2}{*}{ iAC } & Bovine & Improved & Luciano et al. (1999, 2004), Guixue et al. (2001) \\
\hline & & Bovine & None & Aktas et al. (1995) \\
\hline & \multirow[t]{6}{*}{ Forskolin } & Human & Improved & Shu et al. (2008) \\
\hline & & Murine & Improved & $\begin{array}{l}\text { Albuz et al. (2010), Zeng et al. (2013, 2014), } \\
\text { Richani et al. (2014b) }\end{array}$ \\
\hline & & Bovine & Improved & Ali and Sirard (2005), Albuz et al. (2010), Li et al. (2016) \\
\hline & & Bovine & None/Decreased & $\begin{array}{l}\text { Ulloa et al. (2014), Guimaraes et al. (2015), } \\
\text { Bernal-Ulloa et al. (2016) }\end{array}$ \\
\hline & & Ovine & Improved & Rose et al. (2013) \\
\hline & & Ovine & None & Buell et al. (2015) \\
\hline
\end{tabular}

*Relative to standard IVM control. As assessed by embryo development typically to the blastocyst stage.

CNP, C-type natriuretic peptide; dbcAMP, dibutyryl cAMP; iAC, invasive adenylate cyclase; IBMX, 3-isobutyl-1-methylxanthine.

substantial benefit (Table 2). The rationale for moving beyond standard IVM is that oocyte maturation does not occur 'spontaneously' in vivo, but rather is an induced process that occurs in response to a rapid and transient surge in somatic/COC cAMP (Dekel \& Beers 1978).

\section{Standard IVM (low CAMP)}

Standard IVM refers to the isolation of immature COCs from antral follicles and their subsequent maturation in medium without cAMP-modulating agents (Fig. 3A). This method is based on the principles of spontaneous oocyte meiotic maturation described previously (Edwards 1965, Pincus \& Enzmann 1935). Standard IVM systems typically contain FSH or other additives such as EGF, EGF-p and/or LH/hCG (Fig. 3A). FSH leads to a transient rise in COC cAMP (Li et al. 2012) (Fig. 3E). However, if COC collection and processing is slow (see "The oocyte collection phase" section) or if FSH is omitted from IVM, then cAMP levels fall rapidly, resulting in spontaneous meiotic resumption (Aktas et al. 1995, Luciano et al. 2004). In some species, FSH has negligible effects on MII rates and hence oocytes mature spontaneously (e.g. murine, bovine and ovine), whereas in others, FSH significantly improves MII rates, suggesting meiotic induction (e.g. porcine and human). As cAMP hydrolysis is permitted in this system, intra-oocyte cAMP levels decrease (Fig. 3E), leading to inactivation of PKA and rapid progression to GVBD (Norris et al. 2009, Vaccari et al. 2009, Li et al. 2012).

\section{Biphasic IVM (moderate CAMP)}

Biphasic IVM systems use a relatively high concentration of a PDE inhibitor to prevent spontaneous GVBD of COCs upon removal from the follicle for an extended period (e.g. $24 \mathrm{~h}$ or more; Fig. 3B), thereby preserving the moderate cAMP levels stimulated by FSH (Fig. 3E) (Nogueira et al. 2003b, Nogueira et al. 2006, Kawashima et al. 2008). Examples of PDE inhibitors used include: Org9935, cilostamide, milrinone, IBMX and CNP (Table 2). In the second phase, the inhibitor is washed out, decreasing CAMP levels and enabling oocyte maturation (Fig. 3B). In general, biphasic IVM systems lead to modest improvements in oocyte developmental competence, relative to standard IVM (see Table 2 for references).

\section{Induced IVM (moderate cAMP)}

In oocytes that are naturally GV-arrested (e.g. intrafollicular) or artificially GV-arrested (e.g. isolated COCs arrested using a PDE inhibitor), meiosis can be readily induced using natural ligands such as FSH, EGF and EGF-p (Dekel \& Beers 1978, Dekel \& Sherizly 1985, 
Downs et al. 1988). Oocyte maturation is 'induced' as meiotic maturation is inhibited in the absence of such meiosis-stimulating ligands. The actions of these ligands are mediated by CCs, as they induce GVBD in intact explanted follicles or in COCs in vitro, but not in DOs in vitro (Downs et al. 1988, Park et al. 2004). Hence, induced IVM systems typically incorporate the simultaneous application of a meiotic inhibitor and a meiosis-inducing ligand (Fig. 3C) (Thomas et al. 2004b). GVBD and progression to MII occur in the presence of the meiotic inhibitor at moderate-low levels of COC cAMP (Fig. 3E). This system, pioneered by Downs and Eppig (Downs et al. 1988), has been used extensively for decades as a mouse oocyte experimental model to study the cellular and molecular control of meiotic induction (Downs 2010). However, it has not been examined in oocyte developmental competence studies (see Table 2 for references).

\section{Induced IVM (high CAMP)}

The distinguishing feature of this approach to IVM is the inclusion of pharmacological agent(s) that increase COC CAMP or induce the synthesis of large quantities of CAMP in the COC (Fig. 3D). This approach was pioneered by Funahashi $\mathrm{H}$. et al. by treating porcine COCs with dbcAMP, leading to improved subsequent blastocyst yield (Funahashi et al. 1997). Use of dbcAMP has proved highly successful and is now widely used in porcine IVM embryo production systems (Table 2). Other cAMP-elevating agents of note used for this approach include invasive adenylate cyclase (iAC; (Aktas et al. 1995, Luciano et al. 1999)) and forskolin (Ali \& Sirard 2005, Shu et al. 2008). Forskolin, in particular, leads to rapid and large increases in whole COC and intra-oocyte cAMP (Thomas et al. 2002, Bernal-Ulloa et al. 2016) to levels that approximate the spike in COC cAMP levels that occur in vivo in response to LH (Fig. 3E) (Wang et al. 2011). One such approach is simulated physiological oocyte maturation (SPOM; (Albuz et al. 2010, Gilchrist et al. 2015)). The COC cAMP profile in response to these pharmacological agents is usually more acute and notably higher than that achieved by FSH treatment of COCs, as per standard IVM (Albuz et al. 2010). Such induced IVM systems typically incorporate a pre-IVM (Luciano et al. 1999) or biphasic approach (Funahashi et al. 1997) (Fig. 3D), in which COCs are exposed to the cAMP-elevating agent for several hours (e.g. 2 h; (pre-IVM) to up to 22-24h (biphasic)). This is usually followed by an IVM phase lacking pharmacological AC activators, either in the presence (Zeng et al. 2013) or absence of FSH (Sugimura et al. 2015). A PDE inhibitor such as cilostamide can be included in the IVM phase, as used in SPOM version 1 (Albuz et al. 2010) or omitted as per SPOM version 2 (Zeng et al. 2013, Richani et al. 2014b, Zeng et al.
2014, Gilchrist et al. 2015, Li et al. 2016), and in the iAC and dbcAMP approaches (Funahashi et al. 1997, Luciano et al. 1999, Guixue et al. 2001).

It is noteworthy that in all induced IVM (high cAMP) approaches, oocyte meiotic maturation is induced as a result of the elevated CC CAMP, even in the presence of a PDE inhibitor (Dekel et al. 1988, Shu et al. 2008) (this does not or is less likely to occur in biphasic IVM). This may seem paradoxical, as pharmacological stimulation of cAMP synthesis in CCs increases intra-oocyte cAMP by at least an order of magnitude (Thomas et al. 2002), initially preventing GVBD. In fact, this cAMP surge induces CC synthesis of potent meiosis-inducing factors (e.g. EGF-p (Richani et al. 2014b); see 'CC EGF signalling' section), which may recapitulate at least some of the meiosis-inducing events that occur during oocyte maturation in vivo. It is interesting that in induced IVM systems, GVBD occurs at a higher intra-oocyte cAMP concentration than in standard IVM (Wang et al. 2011). Despite the improvements across species in oocyte developmental competence using induced IVM systems (Table 2), this mode of oocyte maturation does not typically improve MII rates, which would be useful in species such as human where IVM MII rates are typically low ( 50\%) (Shu et al. 2008, Zeng et al. 2013).

\section{Oocyte collection phase}

COC collection conditions and the ensuing first hour are paramount to IVM success. This is because a large part of the developmental competence acquired by the oocyte in the follicle can be lost in the first hour. During this period, the oocyte should receive key nutrient support (Frank et al. 2013) and activation of the oocyte's potent PDE should be prevented. Therefore, cAMP-mediated IVM systems require a PDE inhibitor in the oocyte collection medium. Otherwise, upon isolation of the COC, the loss of follicular cGMP will lead to rapid activation of the oocyte's PDE, loss of cAMP (Aktas et al. 1995, Luciano et al. 2004, Albuz et al. 2010), de-activation of PKA, loss of CC-oocyte gap junctions, cessation of oocyte transcription and irreversible resumption of meiosis (Luciano et al. 2011, Li et al. 2012). It is noteworthy that in the IVM literature using porcine and bovine abattoir-sourced oocytes, these COCs are invariably collected and processed in undiluted or high concentration follicular fluid, which provides the COC with nutrient and inhibits the oocyte's PDE. Therefore, the clinical practice of performing IVM oocyte pickups with saline, PBS or simple holding medium is likely to be detrimental to oocyte quality. We have recently demonstrated that the inclusion of IBMX in human oocyte collection medium supports subsequent oocyte maturation and healthy embryo development (Spits et al. 2015). 
Cyclic AMP-mediated IVM and oocyte developmental competence

Publications accumulated over the past decade provide evidence that cAMP-mediated IVM systems can lead to notably improved oocyte quality, compared with standard IVM, as measured by enhanced subsequent pre-implantation embryo development and quality (see Table 2 for citation list). Hence, these novel approaches to IVM are now highly attractive for clinical and commercial applications to bridge the efficiency gap between IVM and IVF. Different CAMP-mediated IVM systems yield differing outcomes. Biphasic IVM and induced IVM (low cAMP) approaches typically lead to modest improvements in blastocyst yield. However, induced IVM systems producing high COC cAMP levels generally lead to larger improvements in oocyte quality (Fig. 3 and Table 2). Induced IVM systems lead to apparently healthy pregnancies and offspring (Akaki et al. 2009, Albuz et al. 2010, Bernal-Ulloa et al. 2016). There are challenges, however, in working with these systems (Gilchrist et al. 2015). First, manipulating oocyte cAMP has major effects on oocyte meiotic kinetics, and hence timing to MII should be assessed carefully under local laboratory conditions (see "Kinetics of meiosis" section). Secondly, IVM systems, where CC and oocyte functions are acutely altered such as SPOM version 1, can be difficult to work with; therefore, strict attention to protocol is needed (Gilchrist et al. 2015). This led to the development of a more user-friendly SPOM version 2 (Zeng et al. 2013, 2014). These issues highlight that, to realise the full potential of these novel approaches to IVM, further refinement of practical aspects of IVM protocols is warranted.

\section{Impact of cAMP-mediated IVM on CCs and the oocyte}

As there is a clear beneficial effect of cAMP-mediated IVM systems on oocyte developmental competence (Table 2), the effect of CAMP-mediated IVM on cellular and molecular aspects of CC and oocyte function is of interest as a means to (1) provide insights into basic mechanisms regulating oocyte quality and (2) offer opportunities to further improve IVM efficiency.

\section{CC microarray analysis}

A microarray analysis of CCs after 6-h exposure to cAMPelevating agents (forskolin + IBMX + dipyridamole; see Table 1) was performed to elucidate cAMP-induced gene networks (Khan et al. 2015). These culture conditions were demonstrated previously to enhance embryo development (Ali \& Sirard 2005). The analysis demonstrated that CAMP significantly and specifically modulated gene expression dynamics including genes involved in cell metabolism, cell communication, signal transduction, steroidogenesis, cell survival and extracellular matrix formation (Khan et al. 2015). Genes involved in cell metabolism such as GFPT2 (glutamine-fructose-6-phosphate transaminase 2) and HK2 (hexokinase 2) were significantly upregulated by the cAMP-elevating agents, as well as genes involved in carbohydrate uptake (SLC2A1, solute carrier family 2-facilitated glucose transporter, members 1 and 3 respectively) and steroidogenesis (STAR, steroidogenic acute regulatory protein). Interestingly, downregulation of EGF pathway genes (AREG, amphiregulin and HAS2, hyaluronan synthase 2), which are involved in cumulus expansion, was observed ((Khan et al. 2015); see the end of "CC EGF signalling" section for temporal effects). Decreased phosphorylation of ERK1/2 supports a possible negative regulatory role of PKA in this process. These findings imply that treatment of COCs with cAMP-elevating agents upregulates genes in cell metabolism, carbohydrate uptake and steroidogenesis, and downregulates genes of the EGF pathway (Khan et al. 2015).

\section{CC-oocyte gap junctional communication}

The central objective of the most recent IVM systems is to preserve CC-oocyte communication, as it is critical to generating a healthy mature oocyte capable of sustaining embryo development (Gilchrist 2011). Under standard IVM conditions, the drop in COC cAMP concentration that occurs after removal of the COC from the antral follicle (Aktas et al. 1995, Albuz et al. 2010) is accompanied by initiation of closure of CC-oocyte GJs (Thomas et al. 2004a). This loss of GJC is attenuated to some extent by the inclusion of FSH in standard IVM media (Atef et al. 2005). FSH stimulates expression of genes encoding connexins including Gja1 (El-Hayek \& Clarke 2015), possibly via a PKAregulated mechanism (Yun et al. 2012). Inhibiting COC cAMP hydrolysis, in either the CC or the oocyte compartment using selective PDE inhibitors, further attenuates the loss of GJC and is usually associated with a delay in GVBD (Luciano et al. 2004, Thomas et al. 2004a). By contrast, using cAMP-elevating agents in IVM, such as forskolin or dbcAMP, not only prevents GJC loss but also maintains full patency for extended periods of IVM (Thomas et al. 2004a, Shu et al. 2008, Albuz et al. 2010, Li et al. 2016). Using cAMP-mediated approaches to preserve CC-oocyte GJCs in IVM is usually associated with an improvement in oocyte developmental competence (see Table 2 for citations). Furthermore, blocking GJs negates any benefits of cAMP-mediated IVM in terms of subsequent embryo development (Atef et al. 2005). The molecular mechanisms underlying the improvement in oocyte quality are not clear; GJ-mediated effects on oocyte metabolism may be important (see "COC metabolism and oocyte antioxidant defence" section), as well as effects on oocyte transcription. As outlined in 
the section on 'Follicle endows the oocyte with developmental competence', addition of cAMP modulators to IVM prevents premature chromatin condensation and permits continued oocyte RNA synthesis. It has been hypothesised that this occurs via a GJ-mediated mechanism (De La Fuente \& Eppig 2001, Luciano et al. 2011).

\section{Kinetics of meiosis}

A founding principle of cAMP-mediated IVM systems is to prevent spontaneous GVBD of oocytes upon removal from antral follicles (Gilchrist \& Thompson 2007) and as such the kinetics of the meiotic cell cycle are notably different in these cAMP-mediated oocyte maturation systems (Fig. 3). GVBD occurs most rapidly under spontaneous IVM (e.g. mouse, $\sim 1 \mathrm{~h}$; bovine, $\sim 6 \mathrm{~h}$ ), where there is uncontrolled loss of intra-oocyte CAMP leading to the activation of MPF. Using biphasic IVM systems, GVBD is prevented as long as the cAMP modulator is present - typically, 22-48 h (Nogueira et al. 2003b, Nogueira et al. 2006). In induced IVM systems, GVBD is typically delayed (but not inhibited) by several hours; for example, from 1 to $3 \mathrm{~h}$ in mouse or from $6-7 \mathrm{~h}$ to $10-12 \mathrm{~h}$ in bovine (Thomas et al. 2004a, Albuz et al. 2010). Delay in time to MII depends on the type, dose and combination of cAMP modulators, but MII is either not delayed (Kim et al. 2008) or delayed by only several hours (Thomas et al. 2004b, Albuz et al. 2010, Rose et al. 2013). However, as GVBD is always delayed, the GVBD to MII interval is commonly shortened using induced or biphasic IVM systems, relative to standard IVM (Thomas et al. 2004b, Kim et al. 2008). There is strong evidence to suggest that this occurs because these IVM systems generate potent meiosis-inducing factors, likely of $\mathrm{CC}$ origin requiring EGFR signalling (see section on 'CC EGF signalling' (Dekel et al. 1988, Downs \& Chen 2008, Albuz et al. 2010)). The net effect of this rapid progression through meiosis is a reduction in meiotic asynchrony, as originally identified by Funahashi et al. (1997) - i.e. a reduction in the time range at which a cohort of oocytes reach MII. Hence, a significant benefit of CAMP-mediated IVM systems is likely to be a reduction in in vitro ageing of IVM oocytes, which may account for their improved developmental competence.

\section{EGF signalling}

The effect of cAMP elevation in CCs in induced IVM systems (e.g. SPOM; Fig. 3D) is mediated, at least in part, by EGF receptor activity. The EGF receptor inhibitor AG1478 blocks GVBD in COCs pulsed with dbcAMP to stimulate maturation (Downs \& Chen 2008). The same effect is also observed in SPOM COCs exposed to AG1478 (Albuz et al. 2010). Moreover, genetic

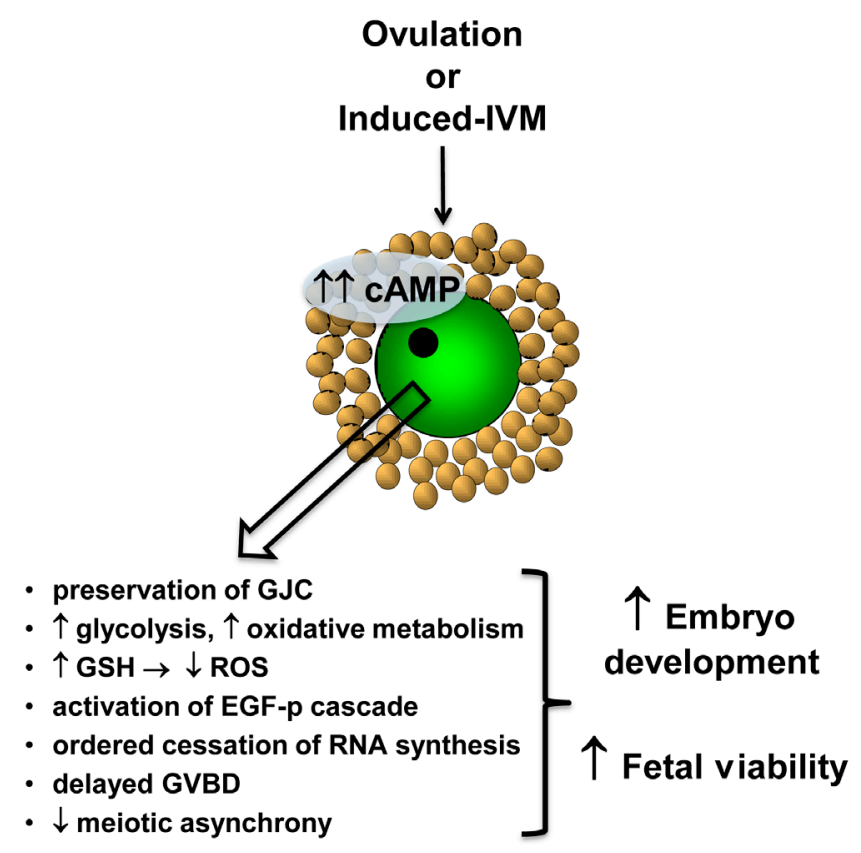

Figure 4 Possible mechanisms by which high levels of COC CAMP during in vivo oocyte maturation or by induced IVM improve oocyte quality. EGF-p, epidermal growth factor-like peptides; GJC, gap junctional communication; GSH, glutathione; GVBD, germinal vesicle breakdown; ROS, reactive oxygen species.

expression analysis of the effect of elevated cAMP in vitro implicates PKA and ERK1/2 pathways, which are interconnected with EGF receptor signalling, as key downstream signalling regulators of cAMP in vitro (Khan et al. 2015). The increased developmental competence of cAMP-mediated IVM oocytes may in part be attributable to the impact of CAMP on EGF pathway signalling in CCs. Standard IVM conditions (including with $\mathrm{FSH}$ ) exhibit perturbed CC expression of EGF-p relative to those matured in vivo (Richani et al. 2013), leading to alterations in COC glucose metabolism and decreased oocyte mitochondrial activity (Richani et al. 2014a). Cyclic AMP elevation using forskolin leads to a large, but very transient, increased expression of CC amphiregulin, epiregulin and betacellulin compared with unstimulated or IBMX-treated COCs (Richani et al. 2014b). However, the increase in expression of EGF-like peptides does not translate into increased activation of the EGF receptor or its downstream target ERK1/2 (Richani et al. 2014b), suggesting that the cAMP-induced spike in EGF-like peptides may impact alternate downstream EGF receptor targets (Chen et al. 2013) or may alter temporal EGFR signalling through negative feedback. The latter hypothesis is supported by evidence showing increased EGF-p expression after 2 hours of forskolin exposure in the mouse, but not at $4 \mathrm{~h}$ (mouse) or $6 \mathrm{~h}$ (cow) (Richani et al. 2014b, Khan et al. 2015). 


\section{COC metabolism and oocyte antioxidant defence}

CAMP-mediated IVM has an effect on CC and oocyte metabolism, consistent with the established relationship between oocyte developmental competency and oocyte metabolism (Thompson et al. 2007). The basic pattern of metabolism during development and maturation of the oocyte is demonstrated as a dynamic process with the consumption of oxygen and the utilisation of nutrients present in culture media - mainly glucose, pyruvate and lactate (Leese 2015). Induced IVM (high CAMP; SPOMv2; Fig. 3D) systems that enhance oocyte quality lead to increased lactate production by COCs over the course of IVM, suggesting stimulation of CC glycolysis (Zeng et al. 2014). Importantly, treating COCs during pre-IVM with forskolin plus IBMX leads to intra-oocyte GSH accumulation in a pre-IVM duration-dependent manner, which is ablated when G)s are blocked (Zeng et al. 2014, Li et al. 2016). This cAMP-mediated increase in $\mathrm{GSH}$ is associated with lower levels of $\mathrm{H}_{2} \mathrm{O}_{2}$, suggesting that a key benefit of cAMP-mediated IVM is an improvement in the oocyte's antioxidant defences requiring $\mathrm{GSH}$ supplied by $\mathrm{CCs}$ ( $\mathrm{Li}$ et al. 2016). As increased GSH levels are highly correlated with oocyte developmental competence (de Matos et al. 1995), this may at least partly explain why pre-maturation with these agents improves oocyte competence. Cyclic AMP-modulated pre-IVM treatments also increase COC oxygen consumption and oocyte oxidative metabolism, associated with an increase in the oocyte redox ratio and a higher ATP:ADP ratio (Zeng et al. 2013, 2014). Therefore, activation of CAMP signalling pathways during oocyte maturation affects not only oocyte metabolism but also oocyte antioxidant defence, in a GJ-dependent manner (Li et al. 2016).

\section{Conclusions}

There is a vast body of literature on the role of cyclic nucleotides in mammalian oocyte function. Their role in the regulation of oocyte meiosis is now clear. More recently we have acquired substantial experimental evidence that the delicate balance of cyclic nucleotides between the somatic and germ cell compartments plays a key role in oocyte developmental competence. Current research is directed to understanding the mechanisms by which cyclic nucleotides improve oocyte quality (Fig. 4). Nonetheless, application of cAMP modulators in IVM can present practical challenges, for example, on the timing of meiosis, and may present regulatory body issues. The challenge therefore to the medical and veterinary disciplines is to capitalise on these new scientific and technological advances to improve the efficacy of IVM, for the benefit of infertile and cancer patients and for domestic animal breeding.

\section{Declaration of interest}

The research programmes of $\mathrm{R} B$ G, M D V, J S and J G T have received commercial funding for the development of IVM technologies from Cook Medical.

\section{Funding}

This work was supported by grants and fellowships from the National Health and Medical Research Council of Australia (1007551, 627007, 1008137 and 1023210) and by the Agency for Innovation through Science and Technology Flanders (IWT) grant number 110680 and the Fund for Scientific Research Flanders (FWO) grant number GO34313.

\section{References}

Akaki Y, Yoshioka K, Noguchi M, Hoshi H \& Funahashi H 2009 Successful piglet production in a chemically defined system for in-vitro production of porcine embryos: dibutyryl cyclic amp and epidermal growth factorfamily peptides support in-vitro maturation of oocytes in the absence of gonadotropins. Journal of Reproduction and Development 55 446-453. (doi:10.1262/jrd.20219)

Aktas H, Wheeler MB, First NL \& Leibfried Rutledge ML 1995 Maintenance of meiotic arrest by increasing [cAMP]i may have physiological relevance in bovine oocytes. Journal of Reproduction and Fertility 105 237-245. (doi:10.1530/jrf.0.1050237)

Albuz FK, Sasseville M, Lane M, Armstrong DT, Thompson JG \& Gilchrist RB 2010 Simulated physiological oocyte maturation (SPOM): a novel in vitro maturation system that substantially improves embryo yield and pregnancy outcomes. Human Reproduction 25 2999-3011. (doi:10.1093/humrep/deq246)

Ali A \& Sirard MA 2005 Protein kinases influence bovine oocyte competence during short-term treatment with recombinant human follicle stimulating hormone. Reproduction 130 303-310. (doi:10.1530/ rep.1.00387)

Anderson E \& Albertini DF 1976 Gap junctions between the oocyte and companion follicle cells in the mammalian ovary. Journal of Cell Biology 71 680-686. (doi:10.1083/jcb.71.2.680)

Appeltant R, Beek J, Vandenberghe L, Maes D \& Van Soom A 2015 Increasing the CAMP concentration during in vitro maturation of pig oocytes improves cumulus maturation and subsequent fertilization in vitro. Theriogenology 83 344-352. (doi:10.1016/ j.theriogenology.2014.09.023)

Ashkenazi H, Cao X, Motola S, Popliker M, Conti M \& Tsafriri A 2005 Epidermal growth factor family members: endogenous mediators of the ovulatory response. Endocrinology 146 77-84. (doi:10.1210/ en.2004-0588)

Atef A, Francois P, Christian V \& Marc-Andre S 2005 The potential role of gap junction communication between cumulus cells and bovine oocytes during in vitro maturation. Molecular Reproduction and Development 71 358-367. (doi:10.1002/mrd.v71:3)

Bagg MA, Nottle MB, Grupen CG \& Armstrong DT 2006 Effect of dibutyryl cAMP on the CAMP content, meiotic progression, and developmental potential of in vitro matured pre-pubertal and adult pig oocytes. Molecular Reproduction and Development 73 1326-1332. (doi:10.1002/(ISSN)1098-2795)

Bernal-Ulloa SM, Heinzmann J, Herrmann D, Hadeler KG, Aldag P, Winkler S, Pache D, Baulain U, Lucas-Hahn A \& Niemann H 2016 Cyclic AMP affects oocyte maturation and embryo development in prepubertal and adult cattle. PLOS ONE 11 e0150264. (doi:10.1371/ journal.pone.0150264)

Buckett WM, Chian RC, Holzer H, Dean N, Usher R \& Tan SL 2007 Obstetric outcomes and congenital abnormalities after in vitro maturation, in vitro fertilization, and intracytoplasmic sperm injection. Obstetrics and Gynecology 110 885-891. (doi:10.1097/01. AOG.0000284627.38540.80) 
Buell M, Chitwood JL \& Ross PJ 2015 cAMP modulation during sheep in vitro oocyte maturation delays progression of meiosis without affecting oocyte parthenogenetic developmental competence. Animal Reproduction Science 154 16-24. (doi:10.1016/j.anireprosci. 2014.12.012)

Chen J, Torcia S, Xie F, Lin CJ, Cakmak H, Franciosi F, Horner K, Onodera C, Song JS, Cedars MI et al. 2013 Somatic cells regulate maternal mRNA translation and developmental competence of mouse oocytes. Nature Cell Biology 15 1415-1423. (doi:10.1038/ncb2873)

Cho WK, Stern S \& Biggers JD 1974 Inhibitory effect of dibutyryl cAMP on mouse oocyte maturation in vitro. Journal of Experimental Zoology 187 383-386. (doi:10.1002/(ISSN)1097-010X)

Conti M, Hsieh M, Zamah AM \& Oh JS 2012 Novel signaling mechanisms in the ovary during oocyte maturation and ovulation. Molecular and Cellular Endocrinology 356 65-73. (doi:10.1016/ j.mce.2011.11.002)

De La Fuente R \& Eppig JJ 2001 Transcriptional activity of the mouse oocyte genome: companion granulosa cells modulate transcription and chromatin remodeling. Developmental Biology 229 224-236. (doi:10.1006/dbio.2000.9947)

de Matos DG, Furnus CC, Moses DF \& Baldassarre H 1995 Effect of cysteamine on glutathione level and developmental capacity of bovine oocyte matured in vitro. Molecular Reproduction and Development 42 432-436. (doi:10.1002/(ISSN)1098-2795)

De Vos M, Smitz J \& Woodruff TK 2014 Fertility preservation in women with cancer. Lancet 384 1302-1310. (doi:10.1016/S01406736(14)60834-5)

Dekel N 1988 Regulation of oocyte maturation. The role of cAMP. Annals of the New York Academy of Sciences 541 211-216. (doi:10.1111/ nyas.1988.541.issue-1)

Dekel N \& Beers WH 1978 Rat oocyte maturation in vitro: relief of cyclic AMP inhibition by gonadotropins. PNAS 75 4369-4373. (doi:10.1073/ pnas.75.9.4369)

Dekel N \& Sherizly I 1985 Epidermal growth factor induces maturation of rat follicle-enclosed oocytes. Endocrinology 116 406-409. (doi:10.1210/ endo-116-1-406)

Dekel N, Lawrence TS, Gilula NB \& Beers WH 1981 Modulation of cell-tocell communication in the cumulus-oocyte complex and the regulation of oocyte maturation by LH. Developmental Biology 86 356-362. (doi:10.1016/0012-1606(81)90193-7)

Dekel N, Galiani D \& Sherizly I 1988 Dissociation between the inhibitory and the stimulatory action of CAMP on maturation of rat oocytes. Molecular and Cellular Endocrinology 56 115-121. (doi:10.1016/03037207(88)90015-9)

Dieci C, Lodde V, Franciosi F, Lagutina I, Tessaro I, Modina SC, Albertini DF, Lazzari G, Galli C \& Luciano AM 2013 The effect of cilostamide on gap junction communication dynamics, chromatin remodeling, and competence acquisition in pig oocytes following parthenogenetic activation and nuclear transfer. Biology of Reproduction 89 68. (doi:10.1095/biolreprod.113.110577)

Downs SM 2010 Regulation of the G2/M transition in rodent oocytes. Molecular Reproduction and Development 77 566-585. (doi:10.1002/ mrd.v77:7)

Downs SM \& Chen J 2008 EGF-like peptides mediate FSH-induced maturation of cumulus cell-enclosed mouse oocytes. Molecular Reproduction and Development 75 105-114. (doi:10.1002/ (ISSN)1098-2795)

Downs SM, Schroeder AC \& Eppig JJ 1986 Developmental capacity of mouse oocytes following maintenance of meiotic arrest in vitro. Gamete Research 15 305-316. (doi:10.1002/(ISSN)1554-3919)

Downs SM, Daniel SA \& Eppig JJ 1988 Induction of maturation in cumulus cell-enclosed mouse oocytes by follicle-stimulating hormone and epidermal growth factor: evidence for a positive stimulus of somatic cell origin. Journal of Experimental Zoology 245 86-96. (doi:10.1002/ (ISSN)1097-010X)

Edwards RG 1965 Maturation in vitro of mouse, sheep, cow, pig, rhesus monkey and human ovarian oocytes. Nature 208 349-351. (doi:10.1038/208349a0)

Egbert JR, Shuhaibar LC, Edmund AB, Van Helden DA, Robinson JW, Uliasz TF, Baena V, Geerts A, Wunder F, Potter LR et al. 2014 Dephosphorylation and inactivation of NPR2 guanylyl cyclase in granulosa cells contributes to the $\mathrm{LH}$-induced decrease in cGMP that causes resumption of meiosis in rat oocytes. Development 141 3594-3604. (doi:10.1242/dev.112219)

El-Hayek S \& Clarke HJ 2015 Follicle-stimulating hormone increases gap junctional communication between somatic and germ-line follicular compartments during murine oogenesis. Biology of Reproduction 9347. (doi:10.1095/biolreprod.115.129569)

Eppig JJ 1982 The relationship between cumulus cell-oocyte coupling, oocyte meiotic maturation \& cumulus expansion. Developmental Biology 89 268-272. (doi:10.1016/0012-1606(82)90314-1)

Eppig JJ 1989 The participation of cyclic adenosine monophosphate (cAMP) in the regulation of meiotic maturation of oocytes in the laboratory mouse. Journal of Reproduction and Fertility. Supplement 38 3-8.

Fan HY \& Richards JS 2010 Minireview: physiological and pathological actions of RAS in the ovary. Molecular Endocrinology 24 286-298. (doi:10.1210/me.2009-0251)

Fan HY, Liu Z, Shimada M, Sterneck E, Johnson PF, Hedrick SM \& Richards JS 2009 MAPK3/1 (ERK1/2) in ovarian granulosa cells are essential for female fertility. Science 324 938-941. (doi:10.1126/ science.1171396)

Franciosi F, Coticchio G, Lodde V, Tessaro I, Modina SC, Fadini R, Dal Canto M, Renzini MM, Albertini DF \& Luciano AM 2014 Natriuretic peptide precursor $C$ delays meiotic resumption and sustains gap junction-mediated communication in bovine cumulusenclosed oocytes. Biology of Reproduction 91 61. (doi:10.1095/ biolreprod.114.118869)

Frank LA, Sutton-McDowall ML, Russell DL, Wang X, Feil DK, Gilchrist RB \& Thompson JG 2013 Effect of varying glucose and glucosamine concentration in vitro on mouse oocyte maturation and developmental competence. Reproduction, Fertility, and Development 25 1095-1104. (doi:10.1071/RD12275)

Funahashi H, Cantley TC \& Day BN 1997 Synchronization of meiosis in porcine oocytes by exposure to dibutyryl cyclic adenosine monophosphate improves developmental competence following in vitro fertilization. Biology of Reproduction 57 49-53. (doi:10.1095/ biolreprod57.1.49)

Gilchrist RB 2011 Recent insights into oocyte-follicle cell interactions provide opportunities for the development of new approaches to in vitro maturation. Reproduction, Fertility, and Development 23 23-31. (doi:10.1071/RD10225)

Gilchrist RB \& Thompson JG 2007 Oocyte maturation: Emerging concepts and technologies to improve developmental potential in vitro. Theriogenology 67 6-15. (doi:10.1016/j.theriogenology. 2006.09.027)

Gilchrist RB, Zeng HT, Wang X, Richani D, Smitz J \& Thompson JG 2015 Reevaluation and evolution of the simulated physiological oocyte maturation system. Theriogenology 84 656-657. (doi:10.1016/j. theriogenology.2015.03.032)

Grupen CG, Fung M \& Armstrong DT 2006 Effects of milrinone and butyrolactone-I on porcine oocyte meiotic progression and developmental competence. Reproduction, Fertility, and Development 18 309-317. (doi:10.1071/RD05125)

Guimaraes AL, Pereira SA, Leme LO \& Dode MA 2015 Evaluation of the simulated physiological oocyte maturation system for improving bovine in vitro embryo production. Theriogenology 83 52-57. (doi:10.1016/j. theriogenology.2014.07.042)

Guixue Z, Luciano AM, Coenen K, Gandolfi F \& Sirard MA 2001 The influence of CAMP before or during bovine oocyte maturation on embryonic developmental competence. Theriogenology 55 1733-1743. (doi:10.1016/S0093-691X(01)00516-7)

Horner K, Livera G, Hinckley M, Trinh K, Storm D \& Conti M 2003 Rodent oocytes express an active adenylyl cyclase required for meiotic arrest. Developmental Biology 258 385-396. (doi:10.1016/S00121606(03)00134-9)

Hsieh M, Lee D, Panigone S, Horner K, Chen R, Theologis A, Lee DC, Threadgill DW \& Conti M 2007 Luteinizing hormone-dependent activation of the epidermal growth factor network is essential for ovulation. Molecular Cell Biology 27 1914-1924. (doi:10.1128/ MCB.01919-06)

Hubbard CJ 1986 Cyclic AMP changes in the component cells of Graafian follicles: possible influences on maturation in the follicleenclosed oocytes of hamsters. Developmental Biology 118 343-351. (doi:10.1016/0012-1606(86)90003-5) 
Hubbard CJ \& Terranova PF 1982 Inhibitory action of cyclic guanosine 5'-phosphoric acid (GMP) on oocyte maturation: dependence on an intact cumulus. Biology of Reproduction 26 628-632. (doi:10.1095/ biolreprod26.4.628)

Hyttel P, Callesen H \& Greve T 1986 Ultrastructural features of preovulatory oocyte maturation in superovulated cattle. Journal of Reproduction and Fertility 76 645-656. (doi:10.1530/jrf.0.0760645)

Jensen JT, Schwinof KM, Zelinski-Wooten MB, Conti M, DePaolo LV \& Stouffer RL 2002 Phosphodiesterase 3 inhibitors selectively block the spontaneous resumption of meiosis by macaque oocytes in vitro. Human Reproduction 17 2079-2084. (doi:10.1093/ humrep/17.8.2079)

Junk SM \& Yeap D 2012 Improved implantation and ongoing pregnancy rates after single-embryo transfer with an optimized protocol for in vitro oocyte maturation in women with polycystic ovaries and polycystic ovary syndrome. Fertility and Sterility 98 888-892. (doi:10.1016/j. fertnstert.2012.06.055)

Kawamura K, Cheng Y, Kawamura N, Takae S, Okada A, Kawagoe Y, Mulders S, Terada Y \& Hsueh AJ 2011 Pre-ovulatory LH/hCG surge decreases C-type natriuretic peptide secretion by ovarian granulosa cells to promote meiotic resumption of pre-ovulatory oocytes. Human Reproduction 26 3094-3101. (doi:10.1093/humrep/der282)

Kawashima I, Okazaki T, Noma N, Nishibori M, Yamashita Y \& Shimada M 2008 Sequential exposure of porcine cumulus cells to FSH and/or $\mathrm{LH}$ is critical for appropriate expression of steroidogenic and ovulation-related genes that impact oocyte maturation in vivo and in vitro. Reproduction 136 9-21. (doi:10.1530/REP-08-0074)

Khan DR, Guillemette C, Sirard MA \& Richard FJ 2015 Transcriptomic analysis of cyclic AMP response in bovine cumulus cells. Physiological Genomics 47 432-442. (doi:10.1152/physiolgenomics. 00043.2015)

Kim JS, Cho YS, Song BS, Wee G, Park JS, Choo YK, Yu K, Lee KK, Han YM \& Koo DB 2008 Exogenous dibutyryl cAMP affects meiotic maturation via protein kinase A activation; it stimulates further embryonic development including blastocyst quality in pigs. Theriogenology 69 290-301. (doi:10.1016/j. theriogenology.2007.09.024)

Kuhtz J, Romero S, De Vos M, Smitz J, Haaf T \& Anckaert E 2014 Human in vitro oocyte maturation is not associated with increased imprinting error rates at LIT1, SNRPN, PEG3 and GTL2. Human Reproduction 29 1995-2005. (doi:10.1093/humrep/deu155)

Laforest MF, Pouliot E, Gueguen L \& Richard FJ 2005 Fundamental significance of specific phosphodiesterases in the control of spontaneous meiotic resumption in porcine oocytes. Molecular Reproduction and Development 70 361-372. (doi:10.1002/mrd.v70:3)

Larsen WJ, Wert SE \& Brunner GD 1986 A dramatic loss of cumulus cell gap junctions is correlated with germinal vesicle breakdown in rat oocytes. Developmental Biology 113 517-521. (doi:10.1016/00121606(86)90187-9)

Leese HJ 2015 History of oocyte and embryo metabolism. Reproduction, Fertility, and Development 27 567-71. (doi:10.1071/RD14278)

Li JX, Mao GK \& Xia GL 2012 FSH modulates PKAI and GPR3 activities in mouse oocyte of COC in a gap junctional communication (GJC)dependent manner to initiate meiotic resumption. PLOS ONE 7 e37835. (doi:10.1371/journal.pone.0037835)

Li HJ, Sutton-McDowall ML, Wang X, Sugimura S, Thompson JG \& Gilchrist RB 2016 Extending prematuration with cAMP modulators enhances the cumulus contribution to oocyte antioxidant defence and oocyte quality via gap junctions. Human Reproduction 31 810-821. (doi:10.1093/humrep/dew020)

Lodde V, Modina S, Maddox-Hyttel P, Franciosi F, Lauria A \& Luciano AM 2008 Oocyte morphology and transcriptional silencing in relation to chromatin remodeling during the final phases of bovine oocyte growth. Molecular Reproduction and Development 75 915-924. (doi:10.1002/ (ISSN)1098-2795)

Lodde V, Franciosi F, Tessaro I, Modina SC \& Luciano AM 2013 Role of gap junction-mediated communications in regulating large-scale chromatin configuration remodeling and embryonic developmental competence acquisition in fully grown bovine oocyte. Journal of Assisted Reproduction and Genetics 30 1219-1226. (doi:10.1007/s10815-0130061-7)

Luciano AM \& Lodde V 2013 Changes of large-scale chromatin configuration during mammalian oocyte differentiation. In Oogenesis, pp 93-108. Eds G Coticchio, DF Albertini \& L De Santis. London, UK: Springer.

Luciano AM, Pocar P, Milanesi E, Modina S, Rieger D, Lauria A \& Gandolfi F 1999 Effect of different levels of intracellular cAMP on the in vitro maturation of cattle oocytes and their subsequent development following in vitro fertilization. Molecular Reproduction and Development 54 86-91. (doi:10.1002/(ISSN)1098-2795)

Luciano AM, Modina S, Vassena R, Milanesi E, Lauria A \& Gandolfi F 2004 Role of intracellular cyclic adenosine 3',5'- monophosphate concentration and oocyte-cumulus cells communications on the acquisition of the developmental competence during in vitro maturation of bovine oocyte. Biology of Reproduction 70 465-472. (doi:10.1095/ biolreprod.103.020644)

Luciano AM, Franciosi F, Modina SC \& Lodde V 2011 Gap junctionmediated communications regulate chromatin remodeling during bovine oocyte growth and differentiation through cAMP-dependent mechanism(s). Biology of Reproduction 85 1252-1259. (doi:10.1095/ biolreprod.111.092858)

Magnusson C \& Hillensjo T 1977 Inhibition of maturation and metabolism in rat oocytes by cyclic amp. Journal of Experimental Zoology 201 139-147. (doi:10.1002/(ISSN)1097-010X)

Masciarelli S, Horner K, Liu C, Park SH, Hinckley M, Hockman S, Nedachi T, Jin C, Conti M \& Manganiello V 2004 Cyclic nucleotide phosphodiesterase 3A-deficient mice as a model of female infertility. Journal of Clinical Investigation 114 196-205. (doi:10.1172/JCI21804)

Mattioli M, Galeati G, Barboni B \& Seren E 1994 Concentration of cyclic AMP during the maturation of pig oocytes in vivo and in vitro. Journal of Reproduction and Fertility $\mathbf{1 0 0}$ 403-409. (doi:10.1530/jrf.0.1000403)

Maurice DH \& Haslam RJ 1990 Molecular basis of the synergistic inhibition of platelet function by nitrovasodilators and activators of adenylate cyclase: inhibition of cyclic AMP breakdown by cyclic GMP. Molecular Pharmacology 37 671-681.

Mayes MA \& Sirard MA 2002 Effect of type 3 and type 4 phosphodiesterase inhibitors on the maintenance of bovine oocytes in meiotic arrest. Biology of Reproduction 66 180-184. (doi:10.1095/ biolreprod66.1.180)

Mehlmann LM, Jones TL \& Jaffe LA 2002 Meiotic arrest in the mouse follicle maintained by a Gs protein in the oocyte. Science $\mathbf{2 9 7}$ 1343-1345. (doi:10.1126/science.1073978)

Nascimento AB, Albornoz MS, Che L, Visintin JA \& Bordignon V 2010 Synergistic effect of porcine follicular fluid and dibutyryl cyclic adenosine monophosphate on development of parthenogenetically activated oocytes from pre-pubertal gilts. Reproduction in Domestic Animals 45 851-859. (doi:10.1111/j.1439-0531.2009.01368.x)

Nogueira D, Albano C, Adriaenssens T, Cortvrindt R, Bourgain C, Devroey P \& Smitz J 2003a Human oocytes reversibly arrested in prophase I by phosphodiesterase type 3 inhibitor in vitro. Biology of Reproduction 69 1042-1052. (doi:10.1095/biolreprod.103.015982)

Nogueira D, Cortvrindt R, De Matos DG, Vanhoutte L \& Smitz J $2003 b$ Effect of phosphodiesterase type 3 inhibitor on developmental competence of immature mouse oocytes in vitro. Biology of Reproduction 69 2045-2052. (doi:10.1095/biolreprod.103.021105)

Nogueira D, Ron-El R, Friedler S, Schachter M, Raziel A, Cortvrindt R \& Smitz J 2006 Meiotic arrest in vitro by phosphodiesterase 3-inhibitor enhances maturation capacity of human oocytes and allows subsequent embryonic development. Biology of Reproduction 74 177-184. (doi:10.1095/biolreprod.105.040485)

Norris RP, Ratzan WJ, Freudzon M, MehImann LM, Krall J, Movsesian MA, Wang H, Ke H, Nikolaev VO \& Jaffe LA 2009 Cyclic GMP from the surrounding somatic cells regulates cyclic AMP and meiosis in the mouse oocyte. Development 136 1869-1878. (doi:10.1242/dev.035238)

Norris RP, Freudzon M, Nikolaev VO \& Jaffe LA 2010 Epidermal growth factor receptor kinase activity is required for gap junction closure and for part of the decrease in ovarian follicle cGMP in response to $\mathrm{LH}$. Reproduction 140 655-662. (doi:10.1530/REP-10-0288)

Olsiewski PJ \& Beers WH 1983 cAMP synthesis in the rat oocyte. Developmental Biology $100 \quad 287-293 . \quad$ (doi:10.1016/00121606(83)90223-3)

Ortega-Hrepich C, Stoop D, Guzman L, Van Landuyt L, Tournaye H, Smitz J \& De Vos M 2013 A "freeze-all" embryo strategy after in vitro maturation: a novel approach in women with polycystic ovary syndrome? Fertility and Sterility 100 1002-1007. (doi:10.1016/j.fertnstert.2013.06.018) 
Park SH \& Yu IJ 2013 Effect of dibutyryl cyclic adenosine monophosphate on reactive oxygen species and glutathione of porcine oocytes, apoptosis of cumulus cells, and embryonic development. Zygote 21 305-313. (doi:10.1017/S0967199412000585)

Park JY, Su YQ, Ariga M, Law E, Jin SL \& Conti M 2004 EGF-like growth factors as mediators of LH action in the ovulatory follicle. Science $\mathbf{3 0 3}$ 682-684. (doi:10.1126/science.1092463)

Perry G 20142013 statistics of embryo collection and transfer in domestic farm animals. Embryo Transfer Newsletter 32 14-26.

Pincus G \& Enzmann EV 1935 The comparative behavior of mammalian eggs in vivo and in vitro: I. The activation of ovarian eggs. Journal of Experimental Medicine 62 665-675. (doi:10.1084/jem.62.5.665)

Ratner A 1976 Effects of follicle stimulating hormone and luteinizing hormone upon cyclic AMP and cyclic GMP levels in rat ovaries in vitro. Endocrinology 99 1496-1500. (doi:10.1210/endo-99-6-1496)

Reinhardt RR, Chin E, Zhou J, Taira M, Murata T, Manganiello VC \& Bondy CA 1995 Distinctive anatomical patterns of gene expression for cGMP-inhibited cyclic nucleotide phosphodiesterases. Journal of Clinical Investigation 95 1528-1538. (doi:10.1172/JCI117825)

Richani D, Ritter LJ, Thompson JG \& Gilchrist RB 2013 Mode of oocyte maturation affects EGF-like peptide function and oocyte competence. Molecular Human Reproduction 19 500-509. (doi:10.1093/molehr/ gat028)

Richani D, Sutton-McDowall ML, Frank LA, Gilchrist RB \& Thompson JG 2014a Effect of epidermal growth factor-like peptides on the metabolism of in vitro- matured mouse oocytes and cumulus cells. Biology of Reproduction 90 49. (doi:10.1095/biolreprod.113.115311)

Richani D, Wang X, Zeng HT, Smitz J, Thompson JG \& Gilchrist RB $2014 b$ Pre-maturation with cAMP modulators in conjunction with EGF-like peptides during in vitro maturation enhances mouse oocyte developmental competence. Molecular Reproduction and Development 81 422-435. (doi:10.1002/mrd.22307)

Richards JS 2001 New signaling pathways for hormones and cyclic adenosine $3^{\prime}, 5^{\prime}$-monophosphate action in endocrine cells. Molecular Endocrinology 15 209-218. (doi:10.1210/me.15.2.209)

Richard FJ, Tsafriri A \& Conti M 2001 Role of phosphodiesterase type 3A in rat oocyte maturation. Biology of Reproduction 65 1444-1451. (doi:10.1095/biolreprod65.5.1444)

Robinson JW, Zhang M, Shuhaibar LC, Norris RP, Geerts A, Wunder F, Eppig JJ, Potter LR \& Jaffe LA 2012 Luteinizing hormone reduces the activity of the NPR2 guanylyl cyclase in mouse ovarian follicles, contributing to the cyclic GMP decrease that promotes resumption of meiosis in oocytes. Developmental Biology 366 308-316. (doi:10.1016/j. ydbio.2012.04.019)

Rose RD, Gilchrist RB, Kelly JM, Thompson JG \& Sutton-McDowall ML 2013 Regulation of sheep oocyte maturation using cAMP modulators. Theriogenology 79 142-148. (doi:10.1016/j.theriogenology. 2012.09.020)

Santiquet N, Papillon-Dion E, Djender N, Guillemette C \& Richard FJ 2014 New elements in the C-type natriuretic peptide signaling pathway inhibiting swine in vitro oocyte meiotic resumption. Biology of Reproduction 91 16. (doi:10.1095/biolreprod.113.114132)

Sasseville M, Albuz FK, Cote N, Guillemette C, Gilchrist RB \& Richard FJ 2009 Characterization of novel phosphodiesterases in the bovine ovarian follicle. Biology of Reproduction 81 415-425. (doi:10.1095/ biolreprod.108.074450)

Sela-Abramovich S, Chorev E, Galiani D \& Dekel N 2005 Mitogenactivated protein kinase mediates luteinizing hormone-induced breakdown of communication and oocyte maturation in rat ovarian follicles. Endocrinology 146 1236-1244. (doi:10.1210/ en.2004-1006)

Shimada M, Hernandez-Gonzalez I, Gonzalez-Robayna I \& Richards JS 2006 Paracrine and autocrine regulation of epidermal growth factorlike factors in cumulus oocyte complexes and granulosa cells: key roles for prostaglandin synthase 2 and progesterone receptor. Molecular Endocrinology 20 1352-1365. (doi:10.1210/me.2005-0504)

Shu YM, Zeng HT, Ren Z, Zhuang GL, Liang XY, Shen HW, Yao SZ, Ke PQ \& Wang NN 2008 Effects of cilostamide and forskolin on the meiotic resumption and embryonic development of immature human oocytes. Human Reproduction 23 504-513. (doi:10.1093/humrep/dem344)

Shuhaibar LC, Egbert JR, Norris RP, Lampe PD, Nikolaev VO, Thunemann M, Wen L, Feil R \& Jaffe LA 2015 Intercellular signaling via cyclic GMP diffusion through gap junctions restarts meiosis in mouse ovarian follicles. PNAS 112 5527-5532. (doi:10.1073/pnas.1423598112)

Somfai T, Kikuchi K, Onishi A, Iwamoto M, Fuchimoto D, Papp AB, Sato E \& Nagai T 2003 Meiotic arrest maintained by cAMP during the initiation of maturation enhances meiotic potential and developmental competence and reduces polyspermy of IVM/IVF porcine oocytes. Zygote 11 199-206. (doi:10.1017/S0967199403002247)

Spits C, Guzman L, Mertzanidou A, Jacobs K, Ortega-Hrepich C, Gilchrist RB, Thompson JG, De Vos M, Smitz J \& Sermon K 2015 Chromosome constitution of human embryos generated after in vitro maturation including 3-isobutyl-1-methylxanthine in the oocyte collection medium. Human Reproduction 30 653-663. (doi:10.1093/ humrep/deu329)

Su YQ, Wigglesworth K, Pendola FL, O'Brien MJ \& Eppig JJ 2002 Mitogen-activated protein kinase activity in cumulus cells is essential for gonadotropin-induced oocyte meiotic resumption and cumulus expansion in the mouse. Endocrinology 143 2221-2232. (doi:10.1210/ endo.143.6.8845)

Sugimura S, Ritter LJ, Rose RD, Thompson JG, Smitz J, Mottershead DG \& Gilchrist RB 2015 Promotion of EGF receptor signaling improves the quality of low developmental competence oocytes. Developmental Biology 403 139-149. (doi:10.1016/j.ydbio.2015.05.008)

Thomas RE, Armstrong DT \& Gilchrist RB 2002 Differential effects of specific phosphodiesterase isoenzyme inhibitors on bovine oocyte meiotic maturation. Developmental Biology 244 215-225. (doi:10.1006/ dbio.2002.0609)

Thomas RE, Armstrong DT \& Gilchrist RB 2004a Bovine cumulus celloocyte gap junctional communication during in vitro maturation in response to manipulation of cell-specific cyclic adenosine 3',5'-monophosophate levels. Biology of Reproduction 70 548-556. (doi:10.1095/biolreprod.103.021204)

Thomas RE, Thompson JG, Armstrong DT \& Gilchrist RB 2004b Effect of specific phosphodiesterase isoenzyme inhibitors during in vitro maturation of bovine oocytes on meiotic and developmental capacity. Biology of Reproduction 71 1142-1149. (doi:10.1095/ biolreprod.103.024828)

Thompson JG \& Gilchrist RB 2013 Improving oocyte maturation in vitro. In Biology and Pathology of the Oocyte: Role in Fertility, Medicine, and Nuclear Reprogramming, 2nd edn, pp 212-223. Eds A Trounson, R Godsen \& U Eichenlaub-Ritter. Cambridge, UK: Cambridge University Press. (doi:10.1017/CBO9781139135030)

Thompson JG, Lane M \& Gilchrist RB 2007 Metabolism of the bovine cumulus-oocyte complex and influence on subsequent developmental competence. Society of Reproduction and Fertility Supplement 64 179-190. (doi:10.5661/rdr-vi-179)

Tsafriri A, Zor U, Lamprech SA \& Lindner HR 1972 In-vitro induction of meiotic division in follicle-enclosed rat oocytes by LH, cyclic AMP and prostaglandin-E2. Journal of Reproduction and Fertility 31 39-50. (doi:10.1530/jrf.0.0310039)

Tsafriri A, Pomerantz SH \& Channing CP 1976 Inhibition of oocyte maturation by porcine follicular fluid: partial characterization of the inhibitor. Biology of Reproduction 14 511-516. (doi:10.1095/ biolreprod14.5.511)

Tsafriri A, Chun SY, Zhang R, Hsueh AJ \& Conti M 1996 Oocyte maturation involves compartmentalization and opposing changes of cAMP levels in follicular somatic and germ cells: studies using selective phosphodiesterase inhibitors. Developmental Biology 178 393-402. (doi:10.1006/dbio.1996.0226)

Ulloa SM, Heinzmann J, Herrmann D, Timmermann B, Baulain U, Grossfeld R, Diederich M, Lucas-Hahn A \& Niemann H 2014 Effects of different oocyte retrieval and in vitro maturation systems on bovine embryo development and quality. Zygote 23 367-377. (doi:10.1017/ s0967199413000658)

Vaccari S, Weeks JL 2nd, Hsieh M, Menniti FS \& Conti M 2009 Cyclic GMP signaling is involved in the luteinizing hormone-dependent meiotic maturation of mouse oocytes. Biology of Reproduction 81 595-604. (doi:10.1095/biolreprod.109.077768)

Vanhoutte L, De Sutter P, Nogueira D, Gerris J, Dhont M \& Van der Elst J 2007 Nuclear and cytoplasmic maturation of in vitro matured human oocytes after temporary nuclear arrest by phosphodiesterase 3-inhibitor. Human Reproduction 22 1239-1246. (doi:10.1093/ humrep/dem007) 
Vanhoutte L, Nogueira D \& De Sutter P 2009a Prematuration of human denuded oocytes in a three-dimensional co-culture system: effects on meiosis progression and developmental competence. Human Reproduction 24 658-669. (doi:10.1093/humrep/den420)

Vanhoutte L, Nogueira D, Dumortier F \& De Sutter P 2009 b Assessment of a new in vitro maturation system for mouse and human cumulusenclosed oocytes: three-dimensional prematuration culture in the presence of a phosphodiesterase 3-inhibitor. Human Reproduction 24 1946-1959. (doi:10.1093/humrep/dep104)

Walls ML, Hunter T, Ryan JP, Keelan JA, Nathan E \& Hart RJ 2015a In vitro maturation as an alternative to standard in vitro fertilization for patients diagnosed with polycystic ovaries: a comparative analysis of fresh, frozen and cumulative cycle outcomes. Human Reproduction 30 88-96. (doi:10.1093/humrep/deu248)

Walls ML, Ryan JP, Keelan JA \& Hart R 2015b In vitro maturation is associated with increased early embryo arrest without impairing morphokinetic development of useable embryos progressing to blastocysts. Human Reproduction 30 1842-1849. (doi:10.1093/ humrep/dev125)

Wang X, Albuz FK, Thompson JG \& Gilchrist RB 2011 Oocyte collection and pre-IVM conditions notably affect mouse oocyte maturation and developmental competence. Proceedings of the 2nd World Congress on Reproductive Biology, Cairns, Australia, October 2011. Abstract \#259.

Wiersma A, Hirsch B, Tsafriri A, Hanssen RG, Van de Kant M, Kloosterboer HJ, Conti M \& Hsueh AJ 1998 Phosphodiesterase 3 inhibitors suppress oocyte maturation and consequent pregnancy without affecting ovulation and cyclicity in rodents. Journal of Clinical Investigation 102 532-537. (doi:10.1172/JCI2566)

Yamashita Y, Kawashima I, Yanai Y, Nishibori M, Richards JS \& Shimada M 2007 Hormone-induced expression of tumor necrosis factor alpha-converting enzyme/A disintegrin and metalloprotease-17 impacts porcine cumulus cell oocyte complex expansion and meiotic maturation via ligand activation of the epidermal growth factor receptor. Endocrinology 148 6164-6175. (doi:10.1210/ en.2007-0195)

Yoshimura Y, Nakamura Y, Oda T, Ubukata Y, Karube M, Koyama N \& Yamada H 1992 Induction of meiotic maturation of follicle-enclosed oocytes of rabbits by a transient increase followed by an abrupt decrease in cyclic AMP concentration. Journal of Reproduction and Fertility 95 803-812. (doi:10.1530/jrf.0.0950803)

Yun SP, Park SS, Ryu JM, Park JH, Kim MO, Lee JH \& Han HJ 2012 Mechanism of PKA-dependent and lipid-raft independent stimulation of Connexin43 expression by oxytoxin in mouse embryonic stem cells. Molecualr Endocrinology 26 1144-1157. (doi:10.1210/ me.2011-1343)

Zeng HT, Ren Z, Guzman L, Wang X, Sutton-McDowall ML, Ritter LJ, De Vos M, Smitz J, Thompson JG \& Gilchrist RB 2013 Heparin and cAMP modulators interact during pre-in vitro maturation to affect mouse and human oocyte meiosis and developmental competence. Human Reproduction 28 1536-1545. (doi:10.1093/ humrep/det086)

Zeng HT, Richani D, Sutton-McDowall ML, Ren Z, Smitz JE, Stokes Y, Gilchrist RB \& Thompson JG 2014 Prematuration with cyclic adenosine monophosphate modulators alters cumulus cell and oocyte metabolism and enhances developmental competence of in vitromatured mouse oocytes. Biology of Reproduction 91 47. (doi:10.1095/ biolreprod.114.118471)

Zhang M, Su YQ, Sugiura K, Xia G \& Eppig J 2010 Granulosa cell ligand NPPC and its receptor NPR2 maintain meiotic arrest in mouse oocytes. Science 330 366-369. (doi:10.1126/science.1193573)

Zhang Q, Liu D, Zhang M, Li N, Lu S, Du Y \& Chen ZJ 2015 Effects of brain-derived neurotrophic factor on oocyte maturation and embryonic development in a rat model of polycystic ovary syndrome. Reproduction Fertility and Development [in press]. (doi:10.1071/rd15131)

Zuccotti M, Giorgi Rossi P, Martinez A, Garagna S, Forabosco A \& Redi CA 1998 Meiotic and developmental competence of mouse antral oocytes. Biology of Reproduction 58 700-704. (doi:10.1095/ biolreprod58.3.700)

Received 21 December 2015

First decision 20 January 2016

Revised manuscript received 6 July 2016

Accepted 15 July 2016 